\title{
Wetter subtropics in a warmer world: Contrasting past and future hydrological cycles
}

\author{
Natalie J. Burls ${ }^{a, b, 1}$ and Alexey V. Fedorov ${ }^{b}$ \\ aDepartment of Atmospheric, Oceanic, \& Earth Sciences, Center for Ocean-Land-Atmosphere Studies, George Mason University, Fairfax, VA 22030; \\ and ${ }^{b}$ Department of Geology and Geophysics, Yale University, New Haven, CT 06511
}

Edited by Jeffrey P. Severinghaus, Scripps Institution of Oceanography, La Jolla, CA, and approved October 11, 2017 (received for review February 28, 2017)

During the warm Miocene and Pliocene Epochs, vast subtropical regions had enough precipitation to support rich vegetation and fauna. Only with global cooling and the onset of glacial cycles some 3 Mya, toward the end of the Pliocene, did the broad patterns of arid and semiarid subtropical regions become fully developed. However, current projections of future global warming caused by $\mathrm{CO}_{2}$ rise generally suggest the intensification of dry conditions over these subtropical regions, rather than the return to a wetter state. What makes future projections different from these past warm climates? Here, we investigate this question by comparing a typical quadrupling-of- $\mathrm{CO}_{2}$ experiment with a simulation driven by sea-surface temperatures closely resembling available reconstructions for the early Pliocene. Based on these two experiments and a suite of other perturbed climate simulations, we argue that this puzzle is explained by weaker atmospheric circulation in response to the different ocean surface temperature patterns of the Pliocene, specifically reduced meridional and zonal temperature gradients. Thus, our results highlight that accurately predicting the response of the hydrological cycle to global warming requires predicting not only how global mean temperature responds to elevated $\mathrm{CO}_{2}$ forcing (climate sensitivity) but also accurately quantifying how meridional sea-surface temperature patterns will change (structural climate sensitivity).

Pliocene | hydrological cycle | climate change | subtropical aridity

F ollowing the Clausius-Clapeyron relation, Earth's atmosphere can hold more water vapor in a warmer climate, past or future. Moreover, in steady state, the hydrological cycle at any one point on the surface of the Earth must obey the following moisture budget, with the residual between precipitation $(P)$ and evaporation $(E)$ balanced by the convergence of moisture in the overlying atmosphere:

$$
P-E=-\nabla \cdot \frac{1}{g} \int_{0}^{p_{s}} v q d p
$$

where $g$ is gravity, $q$ the atmospheric specific humidity, and $v$ the horizontal wind vector integrated across pressure $(p)$ levels from the bottom to the top of the troposphere (as shown schematically in Fig. 1). This budget tells us that in a warmer climate, changes in net precipitation minus evaporation over a specific region, $\delta(P-E)$, will result from either changes in the water content of the air circulating over the region or changes in the circulation itself, or some combination of both:

$$
\delta(P-E)=-\nabla \cdot \frac{1}{g} \int_{0}^{p_{s}} \boldsymbol{v} \delta q d p-\nabla \cdot \frac{1}{g} \int_{0}^{p_{s}} \delta v q d p-\nabla \cdot \frac{1}{g} \int_{0}^{p_{s}} \delta \boldsymbol{v} \delta q d p,
$$

where $\delta$ represents the change in each variable between the warmer climate state and the reference climate state (which in this study is a preindustrial climate).

According to Clausius-Clapeyron, and assuming more or less constant relative humidity as suggested by climate models, $q$ is expected to increase by $\sim 7 \%$ per degree Celsius as climate warms. If large-scale circulation patterns remain similar in strength, i.e., $v$ remains approximately constant, the first term on the right-hand side of Eq. 2 tells us to expect that regions on Earth currently experiencing moisture convergence and hence more precipitation than evaporation will become even wetter, while regions of moisture divergence and net evaporation (e.g., ocean subtropical regions) will become even drier. This is the essence of the familiar paradigm "Wet gets wetter, dry gets dryer" (1). For the subtropics, this thermodynamic scaling, in its simplest form, has different implications over land than ocean, e.g., see ref. 2, since for land regions, there is the constraint that mean $P-E$ values must be positive or near zero. That said, future climate projections generally predict the maintenance or intensification of dry conditions over most subtropical land regions under future global warming $(3,4)$.

Accounting for spatial gradients in surface temperature and humidity changes brings the thermodynamic scaling, based on the first term in Eq. 2, more closely in line with simulations of both future warmth (2) and cold conditions of the Last Glacial Maximum (5). Dynamical $P-E$ changes due to the second term in Eq. 2 are generally regarded as secondary. While climate theory, based on global mean thermodynamic constraints, predicts that we should expect some weakening of large-scale atmospheric overturning circulations in the tropics with global warming (1), in the zonal mean this thermodynamically explained weakening is generally not strong enough to compensate for humidity increases and so the first term in Eq. 2 tends to dominate (3). Circulation changes do however appear to play a role within regional subtropical $P-E$ changes and the poleward expansion of subtropical aridity due to Hadley cell widening in simulations of future climate $(3,6,7)$.

The drier subtropics scenario projected by climate simulations of the future sits in contrast to evidence suggesting that the

\section{Significance}

The subsiding flow of the atmospheric Hadley circulation controls dry conditions over vast subtropical bands where the main arid regions of the globe reside. In the context of future changes in the atmospheric hydrological cycle, understanding precipitation changes in the subtropics is of particular importance given the scarcity of water resources in these locations. A major puzzle arises when contrasting the drier conditions in the subtropics predicted by climate models under global warming scenarios against the wetter conditions seen in reconstructions of past warm climates, including the warm, $\sim 400 \mathrm{ppm} \mathrm{CO}_{2}$, Pliocene. Our modeling results address this puzzle and highlight the importance of correctly predicting how the meridional temperature gradient between the tropics and the subtropics will change with global warming.

Author contributions: N.J.B. and A.V.F. designed research; N.J.B. performed research; and N.J.B. and A.V.F. wrote the paper.

The authors declare no conflict of interest.

This article is a PNAS Direct Submission.

Published under the PNAS license.

${ }^{1}$ To whom correspondence should be addressed. Email: nburls@gmu.edu.

This article contains supporting information online at www.pnas.org/lookup/suppl/doi:10 1073/pnas.1703421114/-/DCSupplemental. 
A

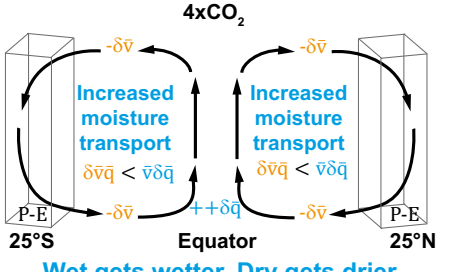

Wet gets wetter, Dry gets drier
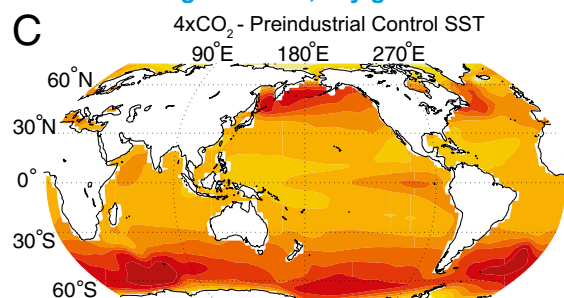

$60^{\circ}$
B

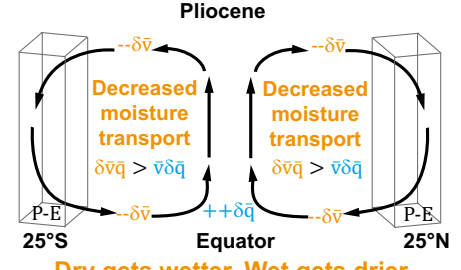

Dry gets wetter, Wet gets drier

Pliocene - Preindustrial Control SST

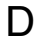

$90^{\circ} \mathrm{E}$

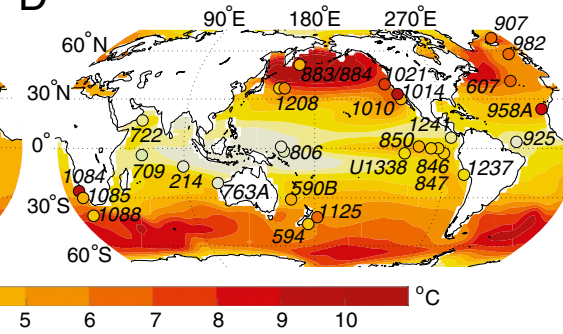

Fig. 1. Different response of the hydrological cycle to global warming due to differences in the meridional structure of the warming. Based on ( $A$ and $C$ ) the $4 \times \mathrm{CO}_{2}$ and $(B$ and $D$ ) Pliocene experiments. The schematics in the top panels summarize the net hydrological cycle response to the SST anomalies (relative to the control) shown in the bottom panels. The reconstructed early Pliocene (4-5 Ma) SST anomalies from sites around the globe (SI Appendix, Table S2) are superimposed on the Pliocene SST change simulated by the coupled simulation with modified cloud albedo which is then used to force the atmosphere-only Pliocene simulation. Surface temperature changes from the atmospheric model over both the land and ocean are shown in SI Appendix, Fig. S1. hydrological cycle behaved in roughly the opposite manner during past warm periods. Wetter subtropics were a salient feature of the warm Miocene, e.g., refs. 8-11-the subsequent aridification in these regions and the expansion of $\mathrm{C}_{4}$ grasslands occurred as climate gradually cooled. Although subtropical aridification appears to have begun in the Miocene and strengthened across the Pliocene and Pleistocene, we focus here on the more recent Pliocene Epoch, primarily because a sufficient number of continuous sea-surface temperature (SST) reconstructions, dating back to the Pliocene from regions across the global ocean, allow us to characterize the nature of large-scale SST gradients (11-13). One of the central large-scale features of Pliocene warmth is that it was polar amplified with meridional SST gradients much weaker than present, including those between the tropics and the subtropics as the warm pool was expanded (13-15). Based on the available SST reconstructions that do extend back into the late Miocene, these large-scale SST gradients appear to have been even weaker during the Tortonian $(11,16,17)$, some 12-7 Ma, at which time modern deserts were covered by shrublands, grasslands, savannas, and woodlands (18). As such, the hydrological cycle mechanism we present for the Pliocene would have been amplified during the Tortonian stage of the Miocene.

With a continental configuration similar to present day, current reconstructions have the Pliocene as the most recent period during which atmospheric $\mathrm{CO}_{2}$ concentrations were close to $400 \mathrm{ppm}$ and comparable to today's values $(11,12,19)$. In this study tropical is defined as the region of zonal- and time-mean moisture convergence situated between $10^{\circ} \mathrm{S}$ and $10^{\circ} \mathrm{N}$ while subtropical refers to the subtropical regions of zonal-mean moisture divergence within latitudinal bands spanning $10-30^{\circ}$ North and South (N\&S) (Fig. 2). Focusing specifically on the subtropics, SI Appendix, Table S1 summarizes published reconstructions of Pliocene climate from a variety of records, spanning all of the continents (see Fig. 4 for sites). While the quality of the age control varies among these reconstructions (e.g., ref. 20), the broad picture which emerges is that the subtropical landmasses were wetter during the Miocene and Pliocene, with tropical savannas and woodland where we see subtropical deserts and arid regions today $(21,22)$, particularly in Africa (23) and Australia (24).

It is important to acknowledge that $\mathrm{CO}_{2}$ fertilization is another factor that can play a role in shaping vegetation changes, particularly in the context of $\mathrm{C}_{4}$ grassland expansion (25). As reconstructions of temperature and moisture availability based on fossil pollen assemblage do not typically account for $\mathrm{CO}_{2}$ fertilization, this issue brings into question the extent to which
Pliocene and Miocene reconstructions reflect a direct effect on plants of changes in atmospheric $\mathrm{CO}_{2}$ concentration versus hydrological cycle changes. Recent studies that do account for the physiological effects of reduced Last Glacial Maximum $\mathrm{CO}_{2}$ concentrations on pollen reconstructions of moisture availability have shown that better agreement is found with independent paleohydrological reconstructions, e.g., ref. 26 and climate simulations (27). That said, the enhancement of photosynthetic carbon uptake in $\mathrm{C}_{3}$ plants under increasing $\mathrm{CO}_{2}$ concentrations appears to be nonlinear with maximum sensitivity in the $\sim 0-250$ ppm range (28). Therefore, with reconstructed Pliocene $\mathrm{CO}_{2}$ concentrations falling within the $\sim 350-450$-ppm range $(11,12$, 19), neglecting the $\mathrm{CO}_{2}$ fertilization signal in pollen-based reconstructions is probably a relatively small source of error since, as summarized in SI Appendix, Table S1, subtropical reconstructions, e.g., ref. 22, tend to align with independent hydroclimate estimates based on other proxies, e.g., ref. 9, including lake-based reconstruction (29).

It is worth noting that modern satellite studies do indicate a global greening trend since 1982 due to anthropogenic $\mathrm{CO}_{2}$ fertilization (30) with evidence for a moderate global increase in maximum foliage cover from 1982 to 2010 within warm arid regions due to $\mathrm{CO}_{2}$ fertilization (31). Climate change projections predict a global increase in net primary productivity (NPP) over the 21st century due to $\mathrm{CO}_{2}$ fertilization $(27,32,33)$; however, this NPP enhancement decreases as $\mathrm{CO}_{2}$ increases and the $\mathrm{CO}_{2}$ fertilization effect becomes saturated (32). Accounting for $\mathrm{CO}_{2}$ fertilization therefore remains an uncertain aspect of Pliocene and Miocene pollen-based hydroclimate reconstructions, demanding future attention. On balance, declining $\mathrm{CO}_{2}$ concentrations, increased aridity, and seasonality are all thought to have played a role in subtropical aridification and $\mathrm{C}_{4}$ grassland expansion across the Pliocene and Miocene and likely acted in concert. It seems unlikely that the $\sim 100$-ppm increase in Pliocene $\mathrm{CO}_{2}$ could have acted alone to support the magnitude of greening reconstructed for the arid subtropical regions. Here we present modeling results illustrating how the changing strength of large-scale meridional SST gradients particularly between the subtropics and the tropics would have acted to aridify the subtropics.

Previous attempts to explain wetter conditions during the Pliocene and the Miocene have tested the idea of a permanent El Niño-like state $(10,21,34)$ with a reduced or absent mean east-west gradient along the equatorial Pacific. While the exact magnitude of this reduction is hotly debated $(17,35-37)$, there are strong indications that this gradient was indeed significantly weaker. Imposing a zero east-west zonal gradient in atmospheric 

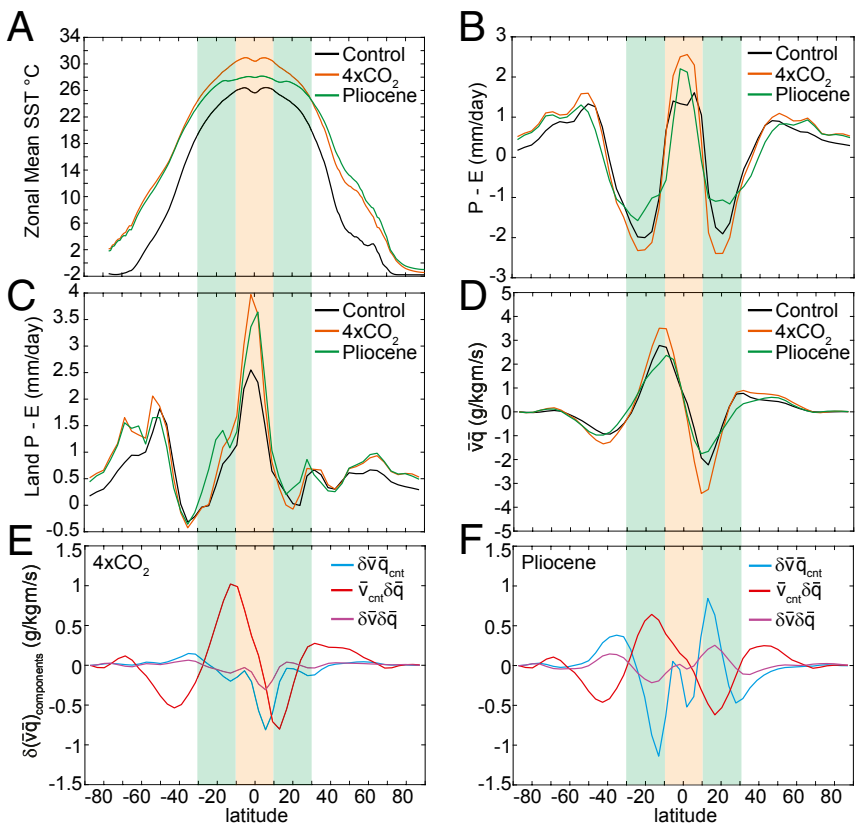

Fig. 2. Zonal-mean components of the hydrological cycle as functions of latitude in the different simulations. The tropics and subtropics are marked as vertical orange and green bands. $(A)$ SST increases fairly uniformly between $30^{\circ} \mathrm{S}$ and $30^{\circ} \mathrm{N}$ in the $4 \times \mathrm{CO}_{2}$ experiment, whereas muted tropical warming (compared with the subtropics and midlatitudes) strongly reduces the meridional SST gradient between the tropics and the subtropics in the Pliocene experiment. $(B)$ Surface precipitation minus evaporation $(P-E)$, while enhanced in the tropics and reduced in the subtropics in the $4 \times \mathrm{CO}_{2}$ experiment (wet gets wetter, dry gets drier), behaves differently in the Pliocene experiment, especially in the subtropics. (C) This contrast in $P-E$ changes between the two simulations holds when restricting the zonal-mean average to only land areas. $(D)$ Moisture transport by time-mean flow $(\bar{q} \bar{v})$ from the subtropics to the tropics while enhanced in the $4 \times \mathrm{CO}_{2}$ experiment is suppressed in the Pliocene experiment. ( $E$ and $F$ ) The contribution of changes in the time-mean humidity $(\bar{q})$ versus circulation $(\bar{v})$ to changes in this moisture transport. While increased atmospheric humidity dominates over circulation changes in the $4 \times \mathrm{CO}_{2}$ experiment $(E)$, weaker Hadley circulation more than compensates the humidity increase in the Pliocene experiment $(F)$, resulting in an overall reduction of the moisture transport $(D)$.

general circulation models (GCM) produces an effect similar to that of a strong modern El Niño with generally wetter conditions over land, especially in midlatitudes over the Americas, but the effects of the imposed change on the subtropical regions both over the ocean and land are mixed (e.g., ref. 38). Moreover, El Niño conditions typically induce drought over the Sahel and parts of Asia (e.g., ref. 39).

Recent observational and fully coupled modeling studies indicate that the immediate cause of the reduced east-west SST gradient along the equator is the reduction of the meridional SST gradient as the two are tightly linked on these timescales $(13,40)$. Consequently, one has to consider not only the zonal but also meridional changes in SST patterns to explain precipitation changes (41). Under the Pliocene Model Intercomparison Project, several fully coupled climate experiments have been performed using state-of-the-art climate models forced with elevated $\mathrm{CO}_{2}$ concentrations (400 ppm) and reconstructed mid-Piacenzian boundary conditions for vegetation, ice sheets, and topography $(15,42,43)$. While these coupled simulations reproduced some polar-amplified warmth, they do not reproduce the full extent of warming suggested by proxy data for the Pliocene Epoch in the middle and high latitudes. They also fail to capture adequately the warming in the equatorial cold tongues and coastal upwelling regions during the Pliocene (12). At the same time, these models may produce too strong a warming in the oceanic warm-pool regions compared with the observations (e.g., ref. 43). As a result, the reduction in large-scale meridional and zonal sea-surface temperature gradients, particularly between the tropics and subtropics, and the general patterns of warming suggested by the paleodata are not fully captured by these coupled simulations, even when resolving the effects associated with changes in $\mathrm{CO}_{2}$, vegetation, ice sheets, and topography.

\section{Results and Discussion}

To explore the effect of the weak Pliocene large-scale SST gradients on the hydrological cycle, we use an atmospheric model driven by the SST field from a fully coupled experiment with modified cloud radiative properties capable of supporting a large-scale ocean temperature pattern that closely resembles early Pliocene reconstructions (Fig. 1D). See refs. 13 and 44 and Methods for details on this early Pliocene simulation, referred to hereafter as the Pliocene simulation. The weak meridional and zonal SST gradients of the Pliocene imply reduced wind-driven poleward heat transport within the ocean subtropical cells (40). Therefore, assuming the partitioning between the atmospheric and ocean components remains approximately constant (45), a change in the required total heat transport, i.e., the meridional gradient in top-of-the-atmosphere radiation, is necessary to maintain such a climate. Interestingly, changes in cloud radiative forcing in response to elevated $\mathrm{CO}_{2}$ can support certain aspects of polar-amplified Pliocene warming (13). However, the magnitude of the $\mathrm{CO}_{2}$ forcing required to reduce the meridional SST gradient to the extent seen in the Pliocene is much greater than the $\sim 400 \mathrm{ppm}$ set by Pliocene reconstructions. Moreover, warm pool as well as global mean temperatures become far too warm. This apparently insufficient sensitivity of cloud radiative forcing to $\mathrm{CO}_{2}$ changes is also seen when attempting to simulate warm Eocene conditions (46) and again changes in cloud radiative forcing are invoked to simulate the equable conditions of the Eocene (47).

Here we contrast the response of the hydrological cycle to the SST structure from the Pliocene simulation against a quadruplingof- $\mathrm{CO}_{2}$ experiment (Fig. 1). As shown in Figs. $1 C$ and $D$ and $2 A$, the clear distinction between these two simulations is that the meridional SST gradient is significantly reduced relative to the preindustrial control in the Pliocene experiment, whereas the warming is more uniform within the $4 \times \mathrm{CO}_{2}$ experiment. The implication for the zonal-mean hydrological response is summarized in Fig. 2. While the $4 \times \mathrm{CO}_{2}$ experiment exhibits the typical "Dry gets dryer, wet gets wetter" response, the Pliocene experiment exhibits roughly the opposite feature, with the subtropical regions becoming wetter and parts of the tropical regions drying as "Dry gets wetter, wet gets drier" (Fig. 2B). When the zonal-mean precipitation is confined only to land regions, both the subtropics and tropics are wetter in the Pliocene (Fig. $2 C$ ). Following Eq. 1, the zonal-mean $P-E$ changes shown in Fig. $2 B$ are associated with changes in the meridional moisture transport such that reduced moisture transport is responsible for the wetter subtropics in the Pliocene simulation. For both simulations equatorward of $40^{\circ} \mathrm{N} \& \mathrm{~S}$ these changes in moisture transport are predominantly due to changes in the time-mean flow $(\bar{q} \bar{v})$ (Fig. $2 D)$ rather than the eddy contribution $\left(\overline{q^{\prime} v^{\prime}}\right)$ (SI Appendix, Fig. S2). Therefore, we base the decomposition shown in Eq. 2 on $\delta \bar{q}$ and $\delta \bar{v}$, where $\delta$ represents the change between the warm climate $\left(4 \times \mathrm{CO}_{2}\right.$ in Fig. $2 E$ and Pliocene in Fig. $\left.2 F\right)$ and the preindustrial control simulation. Fig. $2 E$ and $F$ clearly illustrates that unlike the standard response to $\mathrm{CO}_{2}$-induced warming (Fig. $2 E$ ), reduced meridional circulation between the subtropics and the tropics in the Pliocene simulation more than compensates for the temperature-driven humidity increase, which results in a weakened rather than enhanced equatorward moisture transport.

Fig. $1 A$ and $B$ summarizes this key distinction between the hydrological response in the Pliocene and $\mathrm{CO}_{2}$ experiments. In 
essence, contrasting these two experiments highlights that changes in the strength of the meridional SST gradient, via its control on the strength of the atmospheric meridional Hadley circulation (Fig. 3), plays a key role in the response of the hydrological cycle to warming within our Pliocene experiment. In contrast, poleward of $\sim 50^{\circ} \mathrm{N} \& \mathrm{~S}$, where the eddy components dominate, the zonalmean moisture transport is very similar between the Pliocene and $\mathrm{CO}_{2}$ experiments (SI Appendix, Fig. S2).

Moving away from the zonal-mean view, Fig. 4 compares simulated $P-E$ changes relative to the control for the $\mathrm{CO}_{2}$ versus the Pliocene experiment (see SI Appendix, Fig. S3 for precipitation changes). Consistent with a weakening of the Hadley circulation in the Pliocene experiment, $P-E$ is enhanced within regions where present-day rainfall is suppressed by subsidence. $P-E$ is reduced in many regions of present-day atmospheric uplift, particularly ocean regions corresponding to the modern ITCZ-notable exceptions to this include the Maritime Continent and tropical Africa.

While subtropical subsidence over land and Hadley strength are closely related during winter months in modern climate,
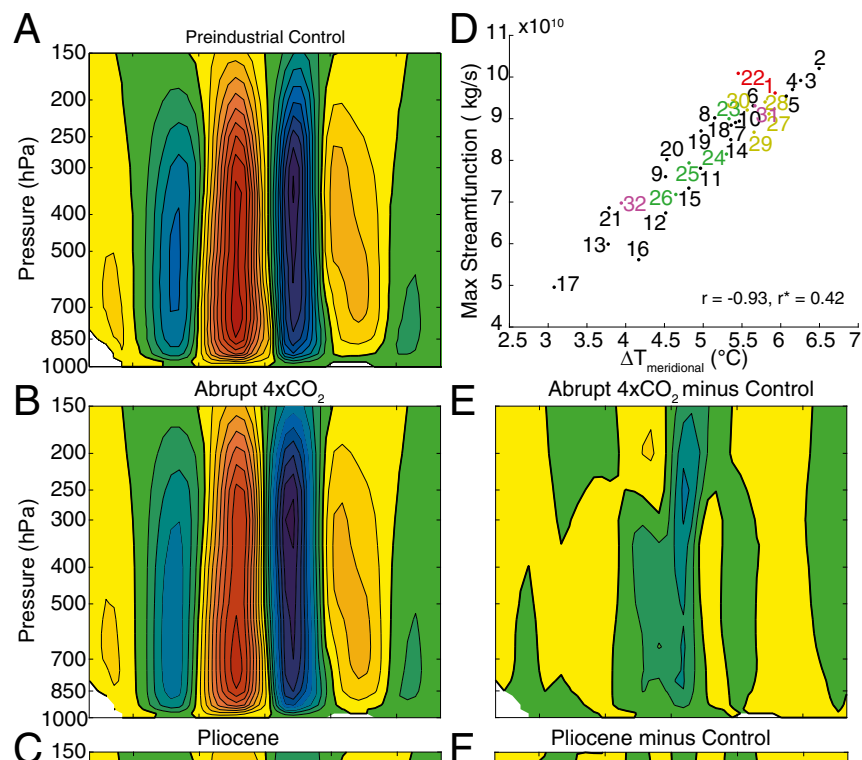

C Pliocene minus Control

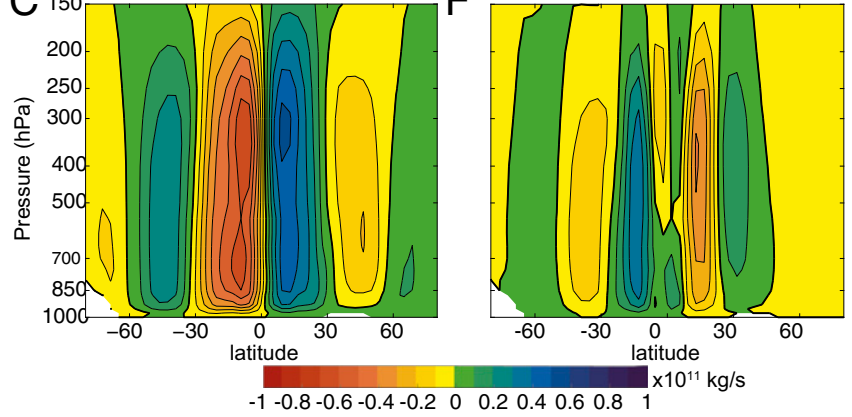

Fig. 3. Hadley circulation in different simulations. The zonal-mean atmospheric meridional stream function for $(A)$ the preindustrial control, $(B)$ the $4 \times \mathrm{CO}_{2}$, and $(C)$ the Pliocene experiments. $(D)$ The relationship between the meridional SST gradient and Hadley circulation strength across the sensitivity experiments. See Methods for the definition of the meridional SST gradient. Color coding is used to help differentiate between the different groups of experiments listed in SI Appendix, Table S3. The difference in the stream function with respect to the control for $(E)$ the $4 \times \mathrm{CO}_{2}$ and $(F)$ the Pliocene experiments. The Pliocene experiment sustains a much weaker Hadley circulation in response to an expanded tropical warm pool and reduced meridional SST gradients. In contrast, relatively uniform warming in the tropics and subtropics in the $4 \times \mathrm{CO}_{2}$ simulation results in small changes in the Hadley circulation strength.
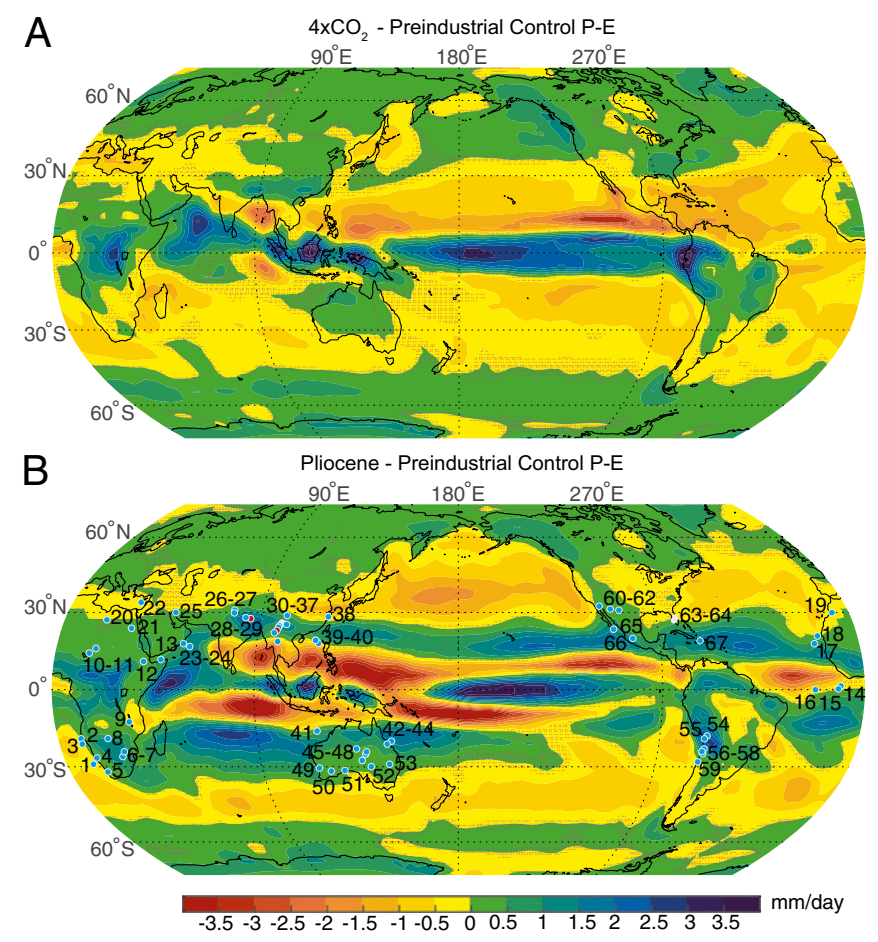

Fig. 4. Global $P-E$ changes. The change in annual mean $P-E$ relative to the preindustrial control for $(A)$ the $4 \times \mathrm{CO}_{2}$ and $(B)$ the Pliocene experiment. Superimposed are the subtropical $\left(\sim 10-30^{\circ} N \& S\right)$ Pliocene paleoclimate reconstructions summarized in SI Appendix, Table S1. Blue sites indicate wetter (or less water-limited) conditions, red indicate drier (more water-limited), gray indicate conditions similar to modern. Statistical significance: Regions without stippling are statistically significant while purple stippling indicates regions falling within two SDs of $20-y$ mean variability during the last $500 \mathrm{y}$ of the control experiment.

monsoon heating over land and the seasonal strengthening of zonal SST gradients within the subtropics (sustained by both atmospheric and oceanic processes) play an important role in the summer strengthening of the subtropical highs over the eastern subtropical oceans affecting subtropical desert regions on the western margins of the continents (48). Consequently, the reduced zonal subtropical SST gradients of the Pliocene help to wet the arid subtropical regions as this monsoon-desert coupling mechanism weakens. This effect is shown in SI Appendix, Figs. S5-S8 comparing summer rainfall, lower tropospheric wind, and sea-level pressure changes within each hemisphere between the abrupt $4 \times \mathrm{CO}_{2}$ and Pliocene experiments. In June-July-August the anticyclonic circulation in the subtropics is weaker in both the North Pacific and Atlantic basins within the Pliocene experiments and is associated with weaker North American and North African monsoons (SI Appendix, Fig. S5 versus SI Appendix, Fig. S6). In the southern hemisphere, in December-January-February weaker subtropical anticyclones over the South Atlantic, South Indian, and South Pacific basins are associated with weaker monsoonal circulation and increased precipitation over the arid western subtropical margins of Southern Africa, Australia, and South America, respectively (SI Appendix, Fig. S7 versus SI Appendix, Fig. S8).

Broadly speaking, this reduced moisture divergence over the subtropics is consistent with geological evidence (Fig. 4 and $S I$ Appendix, Fig. S3 and Table S1) suggesting warmer and wetter Pliocene conditions in Northern and Southern Subtropical Africa, the Arabian Peninsula, Subtropical Asia, Subtropical Australia, and Northern and Southern Subtropical America. Note that certain regional differences, which depend on zonal SST and land surface asymmetries, may be poorly resolved or 
unresolved by the Pliocene simulation as preindustrial topography and vegetation are imposed as boundary conditions. For example, tectonic-driven changes complicate the interpretation and timing of Asian and Indian Monsoon changes, particularly in the Yunnan Province of China, e.g., ref. 49.

The data synthesis presented here focuses on the subtropics, as this is where the weakening of Pliocene SST gradients has robust implications for the hydrological cycle when contrasted against the abrupt $4 \times \mathrm{CO}_{2}$ experiment (Fig. $2 \mathrm{~B}$ and $C$ ). Looking beyond the subtropics, tropical rainfall changes within the Pliocene simulation (SI Appendix, Fig. S3) suggest that tropical convection was more evenly distributed and possibly weaker. This picture is broadly supported by eastern equatorial Pacific dust records suggesting drier conditions in Central America and northern South America (50). Further, reconstructions generally imply that the midlatitude regions of North and South America, as well as Europe, were wetter during the Pliocene $(10,21,22)$. While our Pliocene simulation has increased precipitation over most of the midlatitude landmasses (SI Appendix, Fig. S3), there are some regions of midlatitude drying that may not agree with these reconstructions, particularly when considering $P-E$ (Fig. 4).

To fully explore the effect of meridional SST gradients on the hydrological cycle, Fig. 5 shows results from a suite of simulations across which we systematically reduce the meridional SST gradient by modifying the latitudinal distribution of cloud albedo or increasing atmospheric $\mathrm{CO}_{2}$ concentrations (Methods). The results point to the competition between $(i)$ changes in specific humidity that act to enhance subtropical moisture divergence, and (ii) relaxation of the meridional SST gradient that acts to reduce the strength of atmospheric meridional circulation (SI Appendix, Fig. S4). Under the weak meridional SST gradient of the Pliocene the latter effect dominates, leading to reduced subtropical moisture divergence. Therefore, when it comes to predicting the response of the hydrological cycle within the subtropics to global warming, the warm Pliocene highlights the importance of not only predicting how global mean temperature responds to elevated $\mathrm{CO}_{2}$ (climate sensitivity) but also correctly quantifying how meridional SST patterns will change (structural climate sensitivity). This will largely depend on the strength of cloud feedbacks and the associated changes in cloud radiative forcing, as the first-order control on the strength of large-scale meridional SST gradient changes.

In this study, to produce an SST field resembling the Pliocene, the required change in cloud radiative forcing was superimposed, which begs the question: What could have supported such changes in cloud radiative forcing during the Pliocene? Perhaps, unresolved cloud feedbacks in response to elevated Pliocene $\mathrm{CO}_{2}$ levels (e.g., convective self-aggregation in the tropics) or a different composition of atmospheric aerosols (e.g., ref. 51) affecting cloud radiative properties? This is a pressing question when it comes to evaluating the Pliocene as an analog for future climate change.

\section{Methods}

Climate Model. The numerical experiments analyzed in this study were performed using the Community Earth System Model (CESM 1) forced with preindustrial orography, vegetation, and land-ice cover. The CESM configuration used for each experiment is detailed in SI Appendix, Table S3. The majority of the simulations were performed using the $131 \mathrm{~g} \times 3 \mathrm{v} 7$ configuration designed to facilitate paleoclimate simulations and the long integration time required to reach near-equilibrium. This configuration has T31 atmospheric and land components coupled to ocean and ice components with a horizontal resolution ranging from $\sim 1^{\circ}$ near the equator to $3^{\circ}$ near the poles (T31gx3v7) (52). To test the sensitivity of the perturbed cloud albedo results to model resolutions, a number of experiments were performed with the more computationally expensive $0.9 \times 1.25 \mathrm{gx} 1 \mathrm{v} 6$ configuration whose atmospheric and oceanic components both have a resolution of $\sim 1^{\circ}$.

Global Climate Sensitivity Experiments. Two sets of sensitivity experiments are analyzed: (i) a range of perturbed cloud albedo experiment across which we
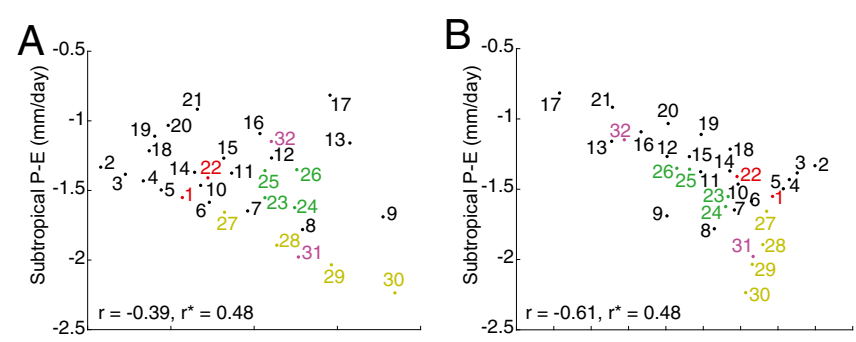

C 10.4

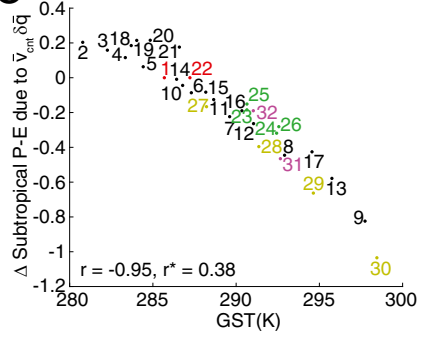

D

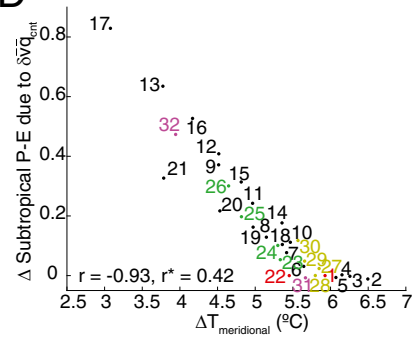

Fig. 5. Climate controls on subtropical $P-E$. ( $A$ and $B)$ The relationship between subtropical $P-E$ (zonal mean between $10^{\circ}$ and $30^{\circ} \mathrm{N} \& \mathrm{~S}$ ) and $(A)$ global mean surface temperature (GST); $(B)$ the meridional SST gradient across the sensitivity experiments. Neither of these variables can account for the spread in subtropical $P-E$ across the simulations conducted. ( $C$ and $D$ ) A strong relationship is seen $(C)$ between GST and the change in subtropical $P-E$ due to humidity-induced changes in the moisture transport (the first term in Eq. 2 when applied to the time-mean flow) and $(D)$ between the meridional SST gradient and the change in subtropical $P-E$ due to circulation-induced changes in the moisture transport (the second term in Eq. 2 when applied to the time-mean flow). Color coding is used to differentiate between the different groups of experiments listed in SI Appendix, Table S3. For all four panels $P-E$ changes are given in millimeters per day $(\mathrm{mm} /$ day)

systemically vary the meridional gradient in cloud albedo keeping $\mathrm{CO}_{2}$ concentration fixed at preindustrial levels and (ii) a range of abrupt $\mathrm{CO}_{2}$ experiments (SI Appendix, Table S3). As outlined in refs. 13 and 40, by scaling the atmospheric liquid and ice water paths (LWP and IP) seen by the shortwave code within distinct latitudinal bands, we alter the optical properties of clouds as they form within the model. Modifying the atmo spheric water path serves as an efficient way of altering the latitudinal SST distribution and the SST gradient between the equator and midlatitudes within a comprehensive GCM by supporting cloud albedo changes of the opposite sign within the tropics and extratropics $(13,40)$. These sensitivity experiments and theoretical considerations $(12,13,40,44)$ suggest that a change in the equator-to-pole gradient of the top-of-the-atmosphere energy budget is required to maintain the structurally different global surface and subsurface temperature field of the Pliocene. However, the exact mechanism maintaining the required change in the meridional structure of cloud radiative forcing (CRF) remains unclear. CRF changes could have occurred via either shortwave and longwave changes realized by changes in a number of cloud properties in addition to liquid and ice water content (e.g., cloud lifetime, particle concentration, and size), and sustained by different Pliocene atmospheric aerosol concentrations or cloud feedbacks to elevated Pliocene $\mathrm{CO}_{2}$ levels poorly resolved by current climate models.

The perturbed cloud albedo experiments are complemented with a set of perturbed $\mathrm{CO}_{2}$ experiments in which we abruptly raise atmospheric $\mathrm{CO}_{2}$ concentrations to $2 \times, 4 \times, 8 \times$, and $16 x$ the preindustrial control levels of $285 \mathrm{ppm}$ without making any modifications to cloud albedo. As outlined in SI Appendix, Table S3, each experiment within both sets of sensitivity experiments has been run for 800 y (200 y in the case of the higher-resolution experiments). This is sufficient for the upper ocean to have reached equilibrium given the multidecadal adjustment timescale of the shallow wind-driven overturning circulation with the deep ocean still experiencing weak drift.

Early Pliocene, Abrupt $4 \times \mathrm{CO}_{2}$, and Preindustrial Control Experiments. To contrast the hydrological response to Pliocene SST forcing against the typical response to elevated $\mathrm{CO}_{2}$-induced warming, we have extended two of the above-mentioned sensitivity experiments to near-equilibrium $[3,000 \mathrm{y}$, at which point the top-of-the-atmosphere (TOA) imbalance falls within \pm 0.1 $\mathrm{Wm}^{-2}$ ]: (i) a modified albedo experiment which best reproduces the early 
Pliocene conditions (Fig. 1) and (ii) the abrupt $4 \times \mathrm{CO}_{2}$ experiment. For the Pliocene experiment the LWP seen by the shortwave code was scaled by 0.4 everywhere poleward of $15^{\circ} \mathrm{N} \& \mathrm{~S}$ (reducing the albedo of low clouds forming in the simulation), while both the LWP and IP were scaled by 3.4 everywhere equatorward of $15^{\circ} \mathrm{N} \& \mathrm{~S}$ (increasing the albedo of all tropical clouds)-see refs. 40 and 44 for further details on the resulting change in TOA radiative forcing. This experiment highlights the changes in TOA radiative forcing required to support the large-scale SST patterns of the Pliocene. To ensure that the arbitrary $15^{\circ} \mathrm{N} \& S$ boundary in imposed cloud optical properties does not lead to spurious effects, particularly over land, we then use the monthly mean SST and sea ice output from the last $100 \mathrm{y}$ of the coupled Pliocene simulation to force the atmospheric component without any water-path modifications. The last $80 \mathrm{y}$ of this $100-\mathrm{y}$ simulation are used in our analysis of the hydrological cycle's response to Pliocene SSTs.

Reconstructing Pliocene SST Gradients. SST reconstructions from sites around the globe spanning the Pliocene have been synthesized by refs. 11 and 12 . We use these data to evaluate early Pliocene SST anomalies relative to the modern (Fig. 1 and SI Appendix, Table S2). Firstly, each time series of reconstructed SST has been interpolated to an even spacing of $2 \mathrm{ky}$. SST anomalies for each site are then defined as the average difference between the interglacial (defined here as above median) values falling between 4 and $5 \mathrm{Ma}$ and interglacial (defined here as above median) values falling between 0 and

1. Held IM, Soden BJ (2006) Robust responses of the hydrological cycle to globa warming. J Clim 19:5686-5699.

2. Byrne MP, O'Gorman PA, Byrne MP (2015) The response of precipitation minus evapotranspiration to climate warming: Why the "wet-get-wetter, dry-get-drier" scaling does not hold over land. J Clim 28:8078-8092.

3. Seager R, Naik N, Vecchi GA (2010) Thermodynamic and dynamic mechanisms for large-scale changes in the hydrological cycle in response to global warming. J Clim 23 4651-4668.

4. Lau WKM, Wu HT, Kim KM (2013) A canonical response of precipitation characteristics to global warming from CMIP5 models. Geophys Res Lett 40:3163-3169.

5. Boos WR (2012) Thermodynamic scaling of the hydrological cycle of the last glacial maximum. J Clim 25:992-1006.

6. Seager R, Vecchi GA (2010) Greenhouse warming and the 21st century hydroclimate of southwestern North America. Proc Natl Acad Sci USA 107:21277-21282.

7. Scheff J, Frierson D (2012) Twenty-first-century multimodel subtropical precipitation declines are mostly midlatitude shifts. J Clim 25:4330-4347

8. Hoetzel S, Dupont L, Schefuß E, Rommerskirchen F, Wefer G (2013) The role of fire in Miocene to Pliocene C4 grassland and ecosystem evolution. Nat Geosci 6:1-5.

9. Dupont LM, Rommerskirchen F, Mollenhauer G, Schefuß E (2013) Miocene to Pliocene changes in South African hydrology and vegetation in relation to the expansion of C4 plants. Earth Planet Sci Lett 375:408-417.

10. Goldner A, Huber M, Diffenbaugh N, Caballero R (2011) Implications of the permanent El Niño teleconnection "blueprint" for past global and North American hydroclimatology. Clim Past 7:723-743.

11. Herbert TD, et al. (2016) Late Miocene global cooling and the rise of modern ecosystems. Nat Geosci 9:843-847.

12. Fedorov AV, et al. (2013) Patterns and mechanisms of early Pliocene warmth. Nature 496:43-49.

13. Fedorov AV, Burls NJ, Lawrence KT, Peterson LC (2015) Tightly linked zonal and meridional sea surface temperature gradients over the past five million years. Nat Geosci 8:975-980.

14. Brierley CM, et al. (2009) Greatly expanded tropical warm pool and weakened Hadley circulation in the early Pliocene. Science 323:1714-1718.

15. Dowsett $\mathrm{HJ}$, et al. (2012) Assessing confidence in Pliocene sea surface temperatures to evaluate predictive models. Nat Clim Chang 2:365-371.

16. LaRiviere JP, et al. (2012) Late Miocene decoupling of oceanic warmth and atmo spheric carbon dioxide forcing. Nature 486:97-100.

17. Zhang YG, Pagani M, Liu Z (2014) A 12-million-year temperature history of the tropical Pacific Ocean. Science 344:84-87.

18. Pound MJ, et al. (2011) A Tortonian (Late Miocene, 11.61-7.25 Ma) global vegetation reconstruction. Palaeogeogr Palaeoclimatol Palaeoecol 300:29-45.

19. Martínez-Botí MA, et al. (2015) Plio-Pleistocene climate sensitivity evaluated using high-resolution $\mathrm{CO}_{2}$ records. Nature 518:49-54.

20. Sniderman JMK, et al. (2016) Pliocene reversal of late Neogene aridification. Proc Nat Acad Sci USA 113:1999-2004.

21. Molnar P, Cane MA (2007) Early Pliocene (pre-lce Age) El Niño-like global climate: Which El Niño? Geosphere 3:337-365.

22. Salzmann U, Haywood AM, Lunt DJ, Valdes PJ, Hill DJ (2008) A new global biome reconstruction and data-model comparison for the Middle Pliocene. Glob Ecol Biogeogr 17:432-447.

23. Levin NE (2015) Environment and climate of early human evolution. Annu Rev Earth Planet Sci 43:405-429.

24. Martin HA (2006) Cenozoic climatic change and the development of the arid vege tation in Australia. J Arid Environ 66:533-563.

25. Cerling TE, Ehleringer JR, Harris JM (1998) Carbon dioxide starvation, the development of C4 ecosystems, and mammalian evolution. Philos Trans $R$ Soc Lond B Biol SC 353:159-171.
$0.5 \mathrm{Ma}$. If the data do not span 0-0.5 Ma, modern SST values are used to calculate the Pliocene SST changes (for the sites from ref. 11 modern SST values from the backtracked geographical location of each site was used to account for any plate movement-a correction mostly affecting Miocene age reconstructions)

Meridional SST Gradient Index. The meridional SST gradient is defined as $\left|\left\langle[S S T(\Theta)]-\left[S S T_{\text {equ }}\right]\right\rangle\right|$, where the angle brackets symbolize the average value between $5^{\circ} \mathrm{N} \& \mathrm{~S}-50^{\circ} \mathrm{N} \& \mathrm{~S}$, the square brackets the zonal mean, and $S S T_{\text {equ }}$ is the SST mean between $5^{\circ} \mathrm{N} \& \mathrm{~S}$. Each latitudinal circle receives equal weight in this calculation.

ACKNOWLEDGMENTS. We thank Richard Seager and another reviewer of this manuscript for their very useful comments, as well as Kale Sniderman and Ulrich Salzmann for helpful discussions and feedback on the manuscript. Computations were performed at the Yale University Faculty of Arts and Sciences High Performance Computing Center. This research is supported by grants from the National Science Foundation (NSF) (AGS-1405272 and AGS-1613318), and National Oceanic and Atmospheric Administration (NOAA) (NA14OAR4310277). N.J.B. is also supported by NSF Grant AGS-1338427, NASA Grant NNX14AM19G, NOAA Grant NA14OAR4310160, and by the Alfred P. Sloan Foundation as a Research Fellow. The CESM project is supported by the NSF and the Department of Energy Office of Science.

26. Prentice IC, Cleator SF, Huang YH, Harrison SP, Roulstone I (2017) Reconstructing ice-age palaeoclimates: Quantifying low-CO2 effects on plants. Glob Planet Change 149:166-176.

27. Scheff J, Seager R, Liu H, Coats S (2017) Are glacials dry? Consequences for paleoclimatology and for greenhouse warming. J Clim 30:6593-6609.

28. Gerhart LM, Ward JK (2010) Plant responses to low [CO2] of the past. New Phytol 188: 674-695.

29. Pound MJ, et al. (2014) Late Pliocene lakes and soils: A global data set for the analysis of climate feedbacks in a warmer world. Clim Past 10:167-180.

30. Zhu Z, et al. (2016) Greening of the Earth and its drivers. Nat Clim Chang 6:791-795.

31. Donohue RJ, Roderick ML, McVicar TR, Farquhar GD (2013) Impact of $\mathrm{CO}_{2}$ fertilization on maximum foliage cover across the globe's warm, arid environments. Geophys Res Lett 40:3031-3035.

32. Cramer W, et al. (2001) Global response of terrestrial ecosystem structure and function to $\mathrm{CO} 2$ and climate change: Results from six dynamic global vegetation models. Glob Chang Biol 7:357-373.

33. Roderick ML, Greve P, Farquhar GD (2015) On the assessment of aridity with changes in atmospheric CO2. Water Resour Res 51:5450-5463.

34. Shukla SP, et al. (2009) Impact of a permanent El Niño (El Padre) and Indian Ocean Dipole in warm Pliocene climates. Paleoceanography 24:PA2221.

35. Ravelo AC, Lawrence KT, Fedorov A, Ford HL (2014) Comment on "A 12-million-year temperature history of the tropical Pacific Ocean". Science 346:1467.

36. O'Brien CL, et al. (2014) High sea surface temperatures in tropical warm pools during the Pliocene. Nat Geosci 7:606-611.

37. Ford HL, Ravelo AC, Dekens PS, LaRiviere JP, Wara MW (2015) The evolution of the equatorial thermocline and the early Pliocene El Padre mean state. Geophys Res Lett 42:4878-4887.

38. Barreiro M, Philander G, Pacanowski R, Fedorov A (2005) Simulations of warm tropical conditions with application to middle Pliocene atmospheres. Clim Dyn 26:349-365.

39. Dai A, Wigley TML (2000) Global patterns of ENSO-induced precipitation. Geophys Res Lett 27:1283-1286.

40. Burls NJ, Fedorov AV (2014) What controls the mean east-west sea surface temperature gradient in the equatorial Pacific: The role of cloud albedo. J Clim 27:2757-2778.

41. Brierley CM, Fedorov AV (2010) Relative importance of meridional and zonal sea surface temperature gradients for the onset of the ice ages and Pliocene-Pleistocene climate evolution. Paleoceanography 25:PA2214-PA2216.

42. Lunt DJ, et al. (2010) Earth system sensitivity inferred from Pliocene modelling and data. Nat Geosci 3:60-64.

43. Brierley C, Burls N, Ravelo C, Fedorov A (2015) Pliocene warmth and gradients. Nat Geosci 8:419-420.

44. Burls NJ, Fedorov AV (2014) Simulating Pliocene warmth and a permanent El Niñolike state: The role of cloud albedo. Paleoceanography 29:893-910.

45. Held IM (2001) The partitioning of the poleward energy transport between the tropical ocean and atmosphere. J Atmos Sci 58:943-948.

46. Huber M, Caballero R (2011) The early Eocene equable climate problem revisited. Clim Past 7:603-633.

47. Lunt DJ, et al. (2013) Warm climates of the past-A lesson for the future? Philos Trans $R$ Soc A Math Phys Eng Sci 371:20130146.

48. Seager R, et al. (2003) Air-sea interaction and the seasonal cycle of the subtropical anticyclones. J Clim 16:1948-1966.

49. Yao Y-F, et al. (2012) Monsoon versus uplift in southwestern China-Late Pliocene climate in Yuanmou Basin, Yunnan. PLoS One 7:e37760.

50. Hovan S (1995) Late Cenozoic atmospheric circulation intensity and climatic history recorded by Eolian deposition in the Eastern Equatorial Pacific Ocean, Leg 138. Proc Ocean Drill Prog Sci Results 138:615-625.

51. Unger N, Yue X (2014) Strong chemistry-climate feedbacks in the Pliocene. Geophys Res Lett 41:527-533.

52. Shields CA, et al. (2012) The low-resolution CCSM4. J Clim 25:3993-4014. 